\title{
La movilidad ciclista como factor de sostenibilidad: breve análisis de su emergencia en la ciudad de Sevilla*
}

\author{
Luis Morales Carballo*
}

\section{Resumen}

Es cada día más necesario implementar, desde una perspectiva compleja y sistémica, estrategias de adaptación al Cambio Global que propicien una mayor resiliencia socioecológica, asuman las perturbaciones y faciliten la auto-ecoorganización de los socioecosistemas urbanos del planeta, incrementando sus niveles de sostenibilidad. Una estrategia importante en esta dirección es el fomento de la movilidad en bicicleta y la restricción de la que se produce en automóvil privado. El ahorro de energía y de contaminación generados, así como el cambio social y mental que subyace, permite afrontar con más garantías la incertidumbre y las perturbaciones asociadas al Cambio Global. La promoción de tiempos lentos se considera además fundamental para devolver la escala humana a la ciudad, maximizar los contactos entre ciudadanos y permitir nuevos usos del espacio y los paisajes, lo cual es signo de una ciudad inteligente. La ciudad de Sevilla está protagonizando importantes avances en esta dirección, que se describen en el artículo.

\section{Palabras clave}

Sostenibilidad; Movilidad ciclista; Perspectiva compleja; Resiliencia; Cambio Global; Movimientos Sociales.

\section{Abstract: Cycling mobility as a factor of sustainability: a brief analysis of its emergence in the city of Seville}

From a complex and systemic approach, it is increasingly necessary to implement adaptation strategies to Global Change that lead to greater socio-ecological resilience, incorporate disruptions and contribute to the self-ecoorganization of urban socio-ecosystems throughout the world, making them more sustainable. Encouraging cycling mobility and restricting private car travel is an important strategy to this end. The resulting energy savings and pollution prevention and the social and mental change underlying this initiative help face the uncertainty and disruptions associated to Global Change with greater guarantees. Moreover, promoting slow times is considered critical to return the human scale to cities, maximize contacts between citizens and allow new uses of space and landscapes, which are signs of an intelligent city. The paper describes the important steps taken by the city of Seville in this direction.

\section{Key words}

Sustainability; Cycling mobility; Complex approach; Resilience; Global Change; Social Movements.

\footnotetext{
Recibido: 17/05/2011; aceptado definitivamente: 30/07/2011

* Resumen adaptado del proyecto final del Máster en Investigación Social Aplicada al Medio Ambiente, que, con el título de La bicicleta como factor de sostenibilidad. Experiencias urbanas europeas y emergencia en Sevilla, fue defendido públicamente en diciembre de 2010 en la Universidad Pablo de Olavide de Sevilla.

*Biólogo. Consultor ambiental. e-mail: estudioluismorales@gmail.com
} 


\section{Fundamentos conceptuales, hipótesis de trabajo y objetivos}

El siglo XX ha conocido un proceso de crecimiento demográfico y de urbanización del planeta que no tiene precedentes en la historia de la Humanidad. En el referido periodo, la población mundial se cuadriplicó, pasando de 1.600 a 6.200 millones, y la población urbana se multiplicó por 12, pasando de unos 250 millones en el año 1900 a algo más de 3.000 millones en el año 2000. Si se considera la evolución de las principales ciudades del mundo, las metrópolis, el crecimiento ha sido mucho más intenso, existiendo en la actualidad alrededor de 500 metrópolis millonarias frente a las tan sólo 10 metrópolis que en el año 1900 rebasaban el millón de habitantes (Fernández Durán, 2008).

Por primera vez en la historia humana, más de la mitad de la población mundial vive en sistemas urbanos, cuyo metabolismo es cada día más exigente en recursos, tanto materiales como energéticos, en paralelo al crecimiento demográfico y urbanizador. La movilidad motorizada, y muy especialmente el uso masivo del automóvil privado, contribuyen muy significativamente al consumo de energía fósil (Fig. 1) y al incremento de este metabolismo.

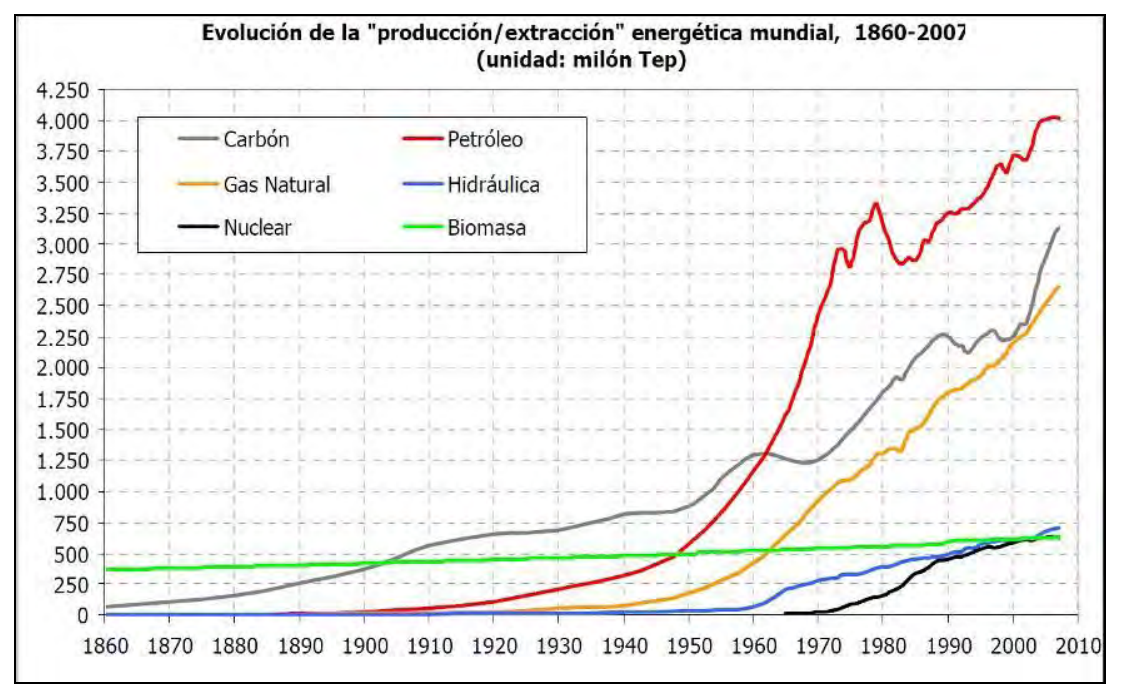

Figura 1: Evolución de los flujos energéticos mundiales en el periodo 1860-2010. Fuente: Murray (2009, cit. en Fernández Durán, 2010).

La huella ecológica, plasmación territorial de este metabolismo, indica (Fig. 2) que desde mediados de la década de 1970 se ha superado la capacidad del planeta de proveer bienes y servicios de forma sostenible en el tiempo, encontrándose en 2007 un 60\% por encima de su capacidad proveedora (WWF, 2010). Los impactos alcanzan una dimensión global. 


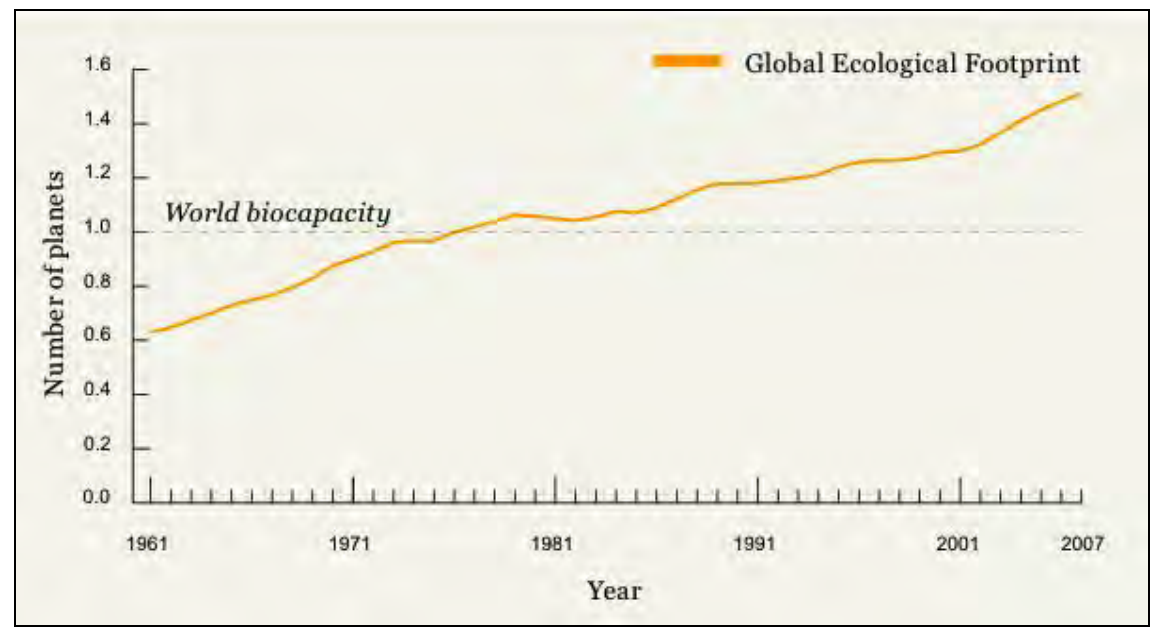

Figura 2: Evolución de la huella ecológica mundial, 1961-2007. Fuente: WWF (2010).

Este desbordamiento de los límites planetarios conllevará, de seguir la tendencia actual, un colapso energético/ecológico mundial y, con él, un colapso económico, social, urbano y territorial, en definitiva, civilizatorio (Fernández Durán, 2008). El desorden se manifestará con especial intensidad en las grandes concentraciones urbanas, que hasta el momento actúan como los espacios clave de apropiación y consumo de todo tipo de recursos (Fernández Durán, 1993).

Para prevenirlo, es necesaria una estrategia de "decrecimiento" (Latouche, 2008; Taibo, 2009 y 2010), la cual implica un nuevo orden de ideas, valores y sensibilidades, una nueva lógica que en definitiva trascienda y ponga fin a la metáfora de la producción, la mitología del crecimiento económico y la supremacía del beneficio económico por encima de cualquier otra consideración, que según Naredo (2003 y 2006) caracterizan al actual sistema económico. Asociado a esta estrategia de decrecimiento emerge el concepto de "lentitud", y la radical reconsideración de los tiempos y los espacios urbanos.

La resiliencia (Holling,1973) es una medida de la capacidad de un sistema de absorber tensiones y perturbaciones, sin alterar significativamente sus características de estructura y funcionalidad, es decir, pudiendo regresar a su estado original una vez que la perturbación ha terminado. Si la entendemos como elasticidad, plasticidad y capacidad de adaptación en un mundo complejo y cambiante, la resiliencia que demuestren los sistemas urbanos de todo el planeta será una de las claves fundamentales para prevenir el referido colapso civilizatorio. Esta demostración de resiliencia es especialmente necesaria ante el proceso emergente de Cambio Global, que crea un marco añadido de incertidumbre e impredictibilidad en la nueva era del Antropoceno (Crutzen, 2002; Fernández Durán, 2010) que el ser humano ha inaugurado con su profunda capacidad transformadora. El Cambio Global (Duarte, 2009) emerge con la crisis de modelo de desarrollo económico, social, científico y tecnológico, que - con gran incidencia en el sistema ecológico y sociocultural, tanto a escala local como global - está provocando la actual civilización urbano-industrial por su incapacidad para asumir la existencia de límites biofísicos en el planeta.

El reto de futuro reside en gestionar y planificar de manera óptima la incertidumbre asociada al Cambio Global, para poder anticipar los riesgos civilizatorios y ponerles coto. Ello sólo puede realizarse desde la "resiliencia", concepto que 
tiene además la potencialidad de robustecer semánticamente el término "sostenibilidad", hoy día prácticamente vacío de contenido debido a su desmesurada utilización, a menudo con intereses incluso contrapuestos. Se ha de trabajar, además, con sistemas socioecológicos, esto es, con la interacción permanente entre sociedades humanas y condiciones ecológicas, y siempre desde una perspectiva compleja. El paradigma de la complejidad (Morin, 1994) surge a partir de la quiebra del paradigma de la ciencia clásica basada en el reduccionismo, la simplicidad y el análisis de las partes de un todo. Desde la perspectiva compleja se aspira a un conocimiento multidimensional abierto a la incertidumbre, la mezcla e incluso la contradicción (Morin, 1984). Se trata de un pensamiento contextual, que asume la fusión del sujeto con su objeto de estudio. Las relaciones e interacciones se tornan fundamentales, así como la presencia de grandes dosis de incertidumbre. Desde esta perspectiva compleja surge la noción de socioecosistema o sistema socioecológico (Fig. 3) para subrayar la íntima relación que guarda el ser humano con su ambiente, regulada por un sinfín de interacciones y bucles. Cabe hablar, pues, no ya de sistemas urbanos, sino de socioecosistemas urbanos.

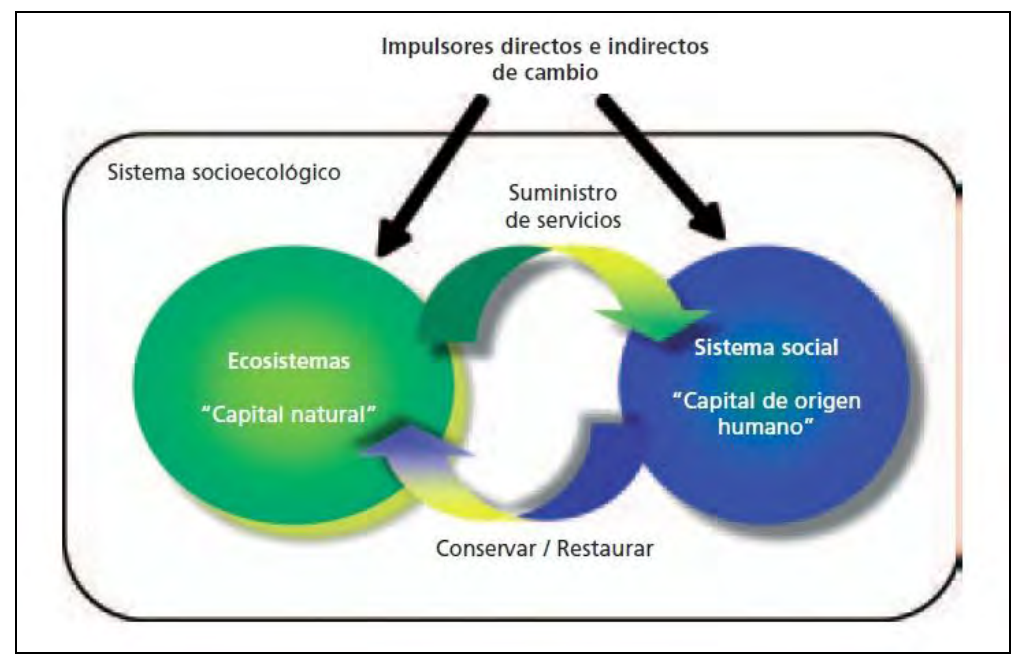

Figura 3: Humanos y ecosistemas constituyen un sistema que interactúan de manera interdependiente a una escala local y global. Fuente: Duarte (2009).

El socioecosistema urbano funciona como un sistema abierto que intercambia materia, energía e información con su entorno. Se dice por ello, también, que las ciudades constituyen "estructuras disipativas" (Prigogine, 1978), las cuales han rebasado, como es sabido, sus límites físicos y son las responsables últimas de la insostenibilidad global verificada. En ellas se ha de actuar en primer lugar para, desde una perspectiva compleja, disminuir su consumo energético asociado a usos exosomáticos (entre ellos la movilidad), moderar su metabolismo urbano $y$, en fin, capacitarlas para hacer frente a los retos de futuro que plantea el Cambio Global. Es todavía posible, en suma, esquivar la "crisis civilizatoria de carácter multidimensional" (Fernández Durán, 2008, p.60) mediante la articulación de estrategias urbanas que propicien una mayor resiliencia socioecológica, asuman las perturbaciones y faciliten la auto-eco-organización del sistema. Ello implica un esfuerzo conjunto y un trabajo sistémico de adaptación al Cambio Global en los socioecosistemas urbanos de todo el planeta.

La hipótesis de trabajo que adopta el Proyecto Final de Máster en el que este artículo se basa es 
que la promoción de los desplazamientos en bicicleta en los socioecosistemas urbanos contribuye a incrementar los niveles de sostenibilidad de éstos, lo que supone un ejercicio de resiliencia socioecológica y de inteligencia compartida ante el proceso emergente de Cambio Global y crisis sistémica de carácter multidimensional.

Este análisis sobre movilidad en bicicleta, movimientos sociales, resiliencia, inteligencia y Cambio Global se particulariza en la ciudad de Sevilla, tomada como caso de estudio tras una primera contextualización en las ciudades europeas.

Los objetivos de este trabajo se exponen a continuación:

1. Aprehender nuevos conceptos y paradigmas aplicados al medio urbano, a partir de la emergencia de la perspectiva compleja y el enfoque interdisciplinar.

2. Analizar específicamente la problemática de la movilidad urbana, desde una perspectiva compleja.

3. Analizar y discutir las actuaciones de promoción y fomento de la movilidad en bicicleta en la ciudad de Sevilla, con especial atención al trabajo de los movimientos sociales y ciudadanos implicados en su defensa.

4. Relacionar el auge de la bicicleta en Sevilla y el ahorro de emisiones de $\mathrm{CO} 2$ con la incorporación de resiliencia socioecológica, aumento de la sostenibilidad, la inteligencia compartida, y las posibilidades de adaptación al Cambio Global y futura crisis energética.

\section{La movilidad urbana y su complejidad}

Fijados los fundamentos conceptuales y epistemológicos, estamos en condiciones de asumir que es absolutamente necesario implementar, desde una perspectiva compleja, estrategias de adaptación al Cambio Global en el actual contexto de Antropoceno, y que para ello nada mejor que crear resiliencia, especialmente en los socioecosistemas urbanos de todo el planeta, debido a que su metabolismo, consumo de energía y devoción por el transporte en el eje horizontal mediante la masiva utilización del automóvil privado, les convierte en los últimos responsables del deterioro constatado.

Del elenco de estrategias urbanas a considerar, una de las más importantes y fundamentales es la de transporte, pues el transporte se encuentra en el corazón de la crisis ecológica, con consecuencias en múltiples direcciones.

La movilidad urbana supone un campo de intervención complejo, en el que se mezclan disciplinas como la Geografía, el Urbanismo, la Ingeniería, la Ecología, la Física, la Sociología, la Psicología y la Economía, entre otras. Es preciso realizar una aproximación a la movilidad urbana desde una perspectiva compleja, adoptando una estrategia general sobre el transporte urbano que esté centrada en el fomento de la movilidad no motorizada (a pie y en bicicleta), y la restricción de la que acontece en automóvil privado (medidas push\&pull). Como es sabido, el modo en que se urbanice un territorio determina las formas de movilidad que emplean los habitantes para desplazarse por ese territorio. Urbanismo y movilidad se encuentran estrechamente interrelacionadas.

Por lo tanto, una estrategia de transporte urbano que ponga el acento en el ahorro energético y en el fomento de la movilidad no motorizada pasa necesariamente por la apuesta por un modelo urbano compacto, de distancias cortas, creador 
de cercanía y en el que la mayoría de los desplazamientos puedan realizarse en medios no motorizados de transporte, en condiciones de plena intermodalidad con sistemas públicos de transporte colectivo (Junta de Andalucía, 2007). Para la adecuada promoción de la bicicleta e integración de la misma en el sistema de transporte de una ciudad es esencial una política general de calmado de tráfico, la ejecución de una red de vías ciclistas segregadas que conecte funcionalmente las distintas zonas de la ciudad, y medidas de estímulo en el ámbito de la educación, administración, etc.

\section{La enfermedad del transporte}

En palabras de Rueda (1995, p.113),

"el problema más importante, el que genera más disfunciones en los sistemas urbanos occidentales es el tránsito de automóviles soportado por la red de carreteras, que se constituye como el principal derrochador de energía (directa o indirecta), y de destrucción del suelo, al servir de motor de nuevos asentamientos urbanos".

No hay ninguna otra actividad humana cuya influencia sobre el entorno presente la combinación de gravedad y multiplicidad de afecciones que caracteriza al transporte (Estevan, 1994). Las raíces del conflicto entre el transporte humano y la naturaleza descansan en la desigual organización estructural que ambas presentan:

"mientras la Naturaleza se organiza principalmente en estructuras verticales y próximas, la especie humana se organiza en estructuras horizontales y lejanas, que descansan sobre alguna forma de transporte, y que muestran una tendencia al parecer irrefrenable a ampliarse a más y más distancia y a hacerse más y más intensas" (ibid., p.2).

Esta ineludible realidad física choca frontalmente con la expansión de la movilidad motorizada, el incremento del número de automóviles y su consideración como objeto de deseo y elemento de exhibición social (Varela, 2008), hasta el punto de que las sociedades occidentales industrializadas han hecho del transporte en el eje horizontal una verdadera patología social o enfermedad.

\section{Precisiones sobre movilidad, accesibilidad y cercanía}

En la fundamental obra Hacia la reconversión ecológica del transporte en España, Estevan y Sanz (1996, p. 43-45), nos aclaran que "la movilidad es un parámetro o variable cuantitativa que mide simple y llanamente la cantidad de desplazamientos efectuados en un determinado sistema o ámbito socioeconómico. [...] La accesibilidad, por su parte, es una variable cualitativa que expresa la facilidad con la que los miembros de una comunidad pueden salvar la distancia que les separa de los lugares en que pueden hallar los medios de satisfacer sus necesidades o deseos".

La accesibilidad debe identificarse, ante todo, con proximidad o cercanía: es decir, una necesidad o deseo son tanto más accesibles (en el plano espacial o geográfico) cuanto menor sea el desplazamiento que es necesario realizar para satisfacerlos. Esta argumentación nos

"conduce a situar la creación de cercanía o proximidad como el objetivo central de toda política de transporte que pretenda tener una orientación ecológica, persiga la reducción de la movilidad motorizada y de la carga de transporte sobre el medio ambiente, manteniendo o mejorando al mismo tiempo la accesibilidad" (ibid., p.44).

Se puede afirmar, en suma, que "en términos de sostenibilidad y de calidad del espacio urbano, la cercanía es un valor primordial a la hora de reducir las necesidades de transporte, por lo que se convierte en el principal método de incremento de la accesibilidad" (Junta de Andalucía, 2007, p.91).

Esta visión exige una nueva cultura del territorio y 
de la práctica urbanística, con profundas implicaciones en la localización de múltiples actividades humanas y económicas en la ciudad o el territorio. Incluso, más aún,

"en la organización de la producción y el consumo, en las formas de satisfacer mil y una necesidades y anhelos individuales y, en general, en la organización socioeconómica global. Una sociedad y una economía ecológicas son aquellas que emulan los principios de la Naturaleza y se adaptan a ellos, en lugar de violentarlos [...]. La creación de proximidad en todos los planos personales, sociales y económicos es la única estrategia de fondo capaz de instaurar un proceso de aproximación continua hacia la plena compatibilización ecológica del transporte" (Estevan, 1994, p. 6).

Más recientemente, la expresión "autosuficiencia conectada" (Gallart, 2009) ha puesto el acento en la necesidad de adaptación a lo existente antes de acudir a lo lejano, en un marco de redes interconectadas.

\section{La necesidad de calmar el tráfico}

Junto con la creación de cercanía o proximidad, resulta fundamental implementar medidas de "calmado de tráfico" (o "pacificación del tráfico") tendentes a moderar tanto la velocidad como la intensidad de la circulación, lo cual es crítico para incrementar la habitabilidad del espacio urbano (Sanz, 2010). Para ello hay que actuar fundamentalmente sobre los automóviles privados, que son los que más significativamente contribuyen a las altas velocidades y elevadas intensidades de circulación. La consecuencia de las medidas de calmado es un espacio urbano más atractivo y seguro para los desplazamientos no motorizados (a pie y en bicicleta), verdadera clave de la movilidad sostenible. En Sanz (2008) se encuentra una excelente recopilación de medidas destinadas al calmado del tráfico.

Las medidas de fomento de la movilidad ciclista deben planificarse conjuntamente con aquellas otras de pacificación del tráfico motorizado, así como con los procesos de peatonalización, lo que evidencia la complejidad e interrelación de las cuestiones de movilidad. Los resultados son, entre otros, un menor metabolismo energético e impacto ambiental, una mayor habitabilidad, sociabilidad y calidad urbana, y, en suma, una mayor complejidad y estabilidad general del socioecosistema urbano.

\section{Algunos beneficios de la movilidad en bicicleta}

Resulta difícil realizar un repaso exhaustivo de las numerosas ventajas que reporta el uso de la bicicleta como medio habitual de transporte en el medio urbano. Cuando la promoción de la movilidad ciclista se planifica simultáneamente con la restricción de la movilidad motorizada en automóvil privado, los beneficios son múltiples y de índole muy diversa, afectando a aspectos ecológicos, sociales, económicos e incluso políticos (cuadro 1). Como se puede comprobar, los beneficios son transversales, diluyen las fronteras, lo que entronca directamente con el paradigma de la complejidad en el que estamos situando la trascendental cuestión de la movilidad urbana.

\section{La promoción de los tiempos lentos}

El estímulo de los desplazamientos en bicicleta (también de los desplazamientos a pie) exige en el fondo una radical reconsideración del paradigma de la movilidad y motorización en la que se desenvuelve la actual civilización urbanoindustrial. Existe un amplio consenso en torno a esta reconsideración (Jacobs, 1967; Illich, 1974; Estevan, 1994; Estevan y Sanz, 1996; Fernández Durán, 2008; Varela, 2008; Sanz, 2008; entre muchos otros). Pero es preciso aclarar que replantearse el concepto de movilidad implicar volver a plantearse también el propio concepto de tiempo (Augé, 2007), y particularmente el de los 
tiempos urbanos, apostando por el disfrute de un modo de vida más pausado y pleno. Ello supone una elección vital enormemente difícil de materializar en la actualidad debido al excesivo protagonismo de algunos aspectos mercantiles de la planificación urbanística que provocan que el mercado organice y especule con todo el territorio. De tal forma que el ciudadano tiene cada vez más difícil ser precisamente ciudadano, la razón de ser de la ciudad, para convertirse en mero cliente.

\begin{tabular}{|c|c|c|c|c|}
\hline & Ecológicos & Sociales & Económicos & Políticos \\
\hline$\frac{\frac{9}{5}}{\frac{0}{0}}$ & Ahorro de energía & Menor estrés & $\begin{array}{l}\text { Reducción del número de } \\
\text { horas laborales perdidas }\end{array}$ & $\begin{array}{c}\text { Reducción de la } \\
\text { dependencia energética }\end{array}$ \\
\hline$\frac{5}{1}$ & Ahorro de contaminación & Aumenta el contacto social & $\begin{array}{l}\text { Reducción de los costes } \\
\text { en materia de salud }\end{array}$ & $\begin{array}{c}\text { Ahorro de recursos no } \\
\text { renovables }\end{array}$ \\
\hline$\frac{\sigma}{\frac{\sigma}{\sigma}}$ & Freno al cambio climático & $\begin{array}{l}\text { Democratización de la } \\
\text { movilidad }\end{array}$ & $\begin{array}{l}\text { Mayor atractivo del centro } \\
\text { urbano para la } \\
\text { implantación de comercios }\end{array}$ & $\begin{array}{c}\text { Mayor accesibilidad general } \\
\text { a los servicios y } \\
\text { equipamientos }\end{array}$ \\
\hline $\begin{array}{l}\frac{0}{5} \\
\frac{5}{6} \\
\frac{8}{6} \\
\frac{8}{2} \\
\frac{8}{3}\end{array}$ & $\begin{array}{c}\text { Mejora de la calidad } \\
\text { ambiental }\end{array}$ & $\begin{array}{c}\text { Aumenta la velocidad } \\
\text { comercial y la zona de } \\
\text { clientela del transporte público }\end{array}$ & $\begin{array}{c}\text { Reducción de los costes } \\
\text { en materia de } \\
\text { infraestructuras de } \\
\text { circulación }\end{array}$ & $\ldots$ \\
\hline & $\begin{array}{l}\text { Conservación de zonas } \\
\text { verdes }\end{array}$ & Conservación de monumentos & $\ldots$ & $\ldots$ \\
\hline
\end{tabular}

Cuadro 1: Beneficios de la movilidad en bicicleta. Elaboración propia.

\section{La promoción de los tiempos lentos}

El estímulo de los desplazamientos en bicicleta (también de los desplazamientos a pie) exige en el fondo una radical reconsideración del paradigma de la movilidad y motorización en la que se desenvuelve la actual civilización urbanoindustrial. Existe un amplio consenso en torno a esta reconsideración (Jacobs, 1967; Illich, 1974; Estevan, 1994; Estevan y Sanz, 1996; Fernández Durán, 2008; Varela, 2008; Sanz, 2008; entre muchos otros). Pero es preciso aclarar que replantearse el concepto de movilidad implicar volver a plantearse también el propio concepto de tiempo (Augé, 2007), y particularmente el de los tiempos urbanos, apostando por el disfrute de un modo de vida más pausado y pleno. Ello supone una elección vital enormemente difícil de materializar en la actualidad debido al excesivo protagonismo de algunos aspectos mercantiles de la planificación urbanística que provocan que el mercado organice y especule con todo el territorio. De tal forma que el ciudadano tiene cada vez más difícil ser precisamente ciudadano, la razón de ser de la ciudad, para convertirse en mero cliente.

Por ello es precisamente importante la promoción de los desplazamientos en bicicleta, y en general de toda la movilidad no motorizada, puesto que permite reconsiderar los tiempos y los espacios urbanos, apostando por la cercanía, la lentitud y el decrecimiento (en consumo de energía, en accidentes, en estrés, en insatisfacción, etc.). Pero no sólo se trata de lentitud, sino también y muy fundamentalmente de emociones: andar, callejear, deambular a paso lento por el espacio público de las ciudades, rehabilitar el espacio urbano, descubrir nuevos paisajes y paisanajes. 
Con ello devuelve a la ciudad su ancestral escala humana (Augé, 2009), multiplica los contactos entre sus habitantes y trasciende las jerarquías sociales.

Muy significativamente, los tiempos lentos permiten una nueva consideración de los paisajes urbanos, especialmente de los fundantes. Los paisajes se mueven con cada pedalada, y facilitan una interacción con el usuario que está ausente de la movilidad motorizada, mucho más rígida y atada a unos itinerarios fijados de antemano. Esta interacción entre el ciclista y el paisaje también se observa en la movilidad peatonal, igualmente libre y sometida a imprevistos cambios de itinerarios y alteraciones de la marcha.

Los desplazamientos a pie y en bicicleta contribuyen de una manera extraordinaria a "verse, encontrarse, socializar las calles, reconstruir lugares de vida y soñar la ciudad. Hoy, cambiar la vida es cambiar la ciudad" (ibid., p.19). Tan estrecha es la relación entre la movilidad no motorizada y los tiempos lentos, que se suele decir que "montar en bicicleta es aprender a administrar el tiempo, tanto el tiempo corto del día o de la etapa, como el tiempo largo de los años que se acumulan" (ibid., p. 41).

La ciudad, como cualquier ser vivo, está sometida al envejecimiento.

"Saber envejecer dignamente, remozándose con equilibrados compases, es uno de los caracteres más significativos de una ciudad inteligente. [...] Por otro lado, una ciudad inteligente en la gestión del tiempo será también aquella que, desde su propia morfología, sepa responder adecuadamente a los diferentes tiempos de sus ciudadanos (tiempo de los niños, tiempo de los paseantes, tiempo de los ejecutivos y productores, tiempo de los mayores, tiempo de los cuidados, tiempo de las creencias,...)" (Ojeda, 2009, p.10).

\section{La bicicleta en la ciudad de Sevilla}

El abordaje metodológico realizado para estudiar y poner en perspectiva el fuerte incremento de la movilidad ciclista en la ciudad de Sevilla en los últimos 4 años ha consistido en la revisión bibliográfica de varios documentos ${ }^{1}$ esenciales relacionados con la promoción de la bicicleta en Sevilla, de los que se han obtenido datos cuantitativos y consideraciones legales, de diseño y organizativas. El análisis se ha completado posteriormente con una entrevista participada a 2 de los más importantes conocedores de la realidad ciclista en Sevilla, Ricardo Marqués ${ }^{2}$ y José García Cebrián ${ }^{3}$, y con matices y contextualizaciones procedentes de la propia experiencia. Estas incorporaciones enriquecen el proceso de conocimiento, que estaría incompleto con la simple toma de datos o revisión bibliográfica. Pueden interpretarse además como técnicas que procuran una ecología de los saberes y un conocimiento situado que permiten hacer emerger las cuestiones habitualmente soterradas por los discursos oficiales y la sociología de las ausencias (Sousa Santos, 2005).

\footnotetext{
${ }^{1}$ Los documentos analizados han sido: "Bases y Estrategias para la integración de la Bicicleta en la Movilidad Urbana de Sevilla" (Gerencia de Urbanismo, 2005); Plan de la Bicicleta de Sevilla 2007-2010 (Gerencia de Urbanismo, 2007); Ordenanza de Circulación de Peatones y Ciclistas de la ciudad de Sevilla (BOP No 117, 2008); y "Estudio sobre el Uso de la Bicicleta en Sevilla" (Delegación de Infraestructuras para la Sostenibilidad, 2010).

${ }^{2}$ Líder de A Contramano, Asamblea Ciclista de Sevilla, desde su constitución en 1987. Ha participado en la elaboración del Pacto Andaluz de la Bicicleta, ha sido uno de los redactores del documento de Bases y Estrategias para la Integración de la Bicicleta en la Movilidad Urbana de Sevilla, forma parte de la Comisión Cívica de la Bicicleta, y es un habitual articulista, promotor y divulgador de iniciativas de fomento de la movilidad en bicicleta.

${ }^{3} \mathrm{Ha}$ sido director del Área Observatorio y Control de Procesos de la Gerencia de Urbanismo, cargo desde el que ha dirigido la elaboración de las Bases y Estrategias para la Integración de la Bicicleta en la Movilidad Urbana de Sevilla, y del Plan de la Bicicleta de Sevilla. Recientemente ha dirigido el Congreso Velocity 2011, El Ciclo de la Vida, celebrado en Sevilla en marzo de 2011.
} 


\section{Revisión bibliográfica}

El documento "Bases y Estrategias para la integración de la Bicicleta en la Movilidad Urbana de Sevilla" (Gerencia de Urbanismo, 2005) facilitó el camino a las actuaciones municipales de fomento de la bicicleta. Constituye un muy completo estudio sobre las posibilidades de incorporación de la bicicleta en la movilidad de Sevilla y la definición de criterios y medidas a implementar para incrementar su uso. El documento desarrolla las líneas estratégicas que han permitido ejecutar la actual red de $120 \mathrm{~km}$ de vías ciclistas en los distintos horizontes, define los itinerarios principales de la ciudad, y finalmente detalla el diseño de la red. Hay 2 criterios generales que han resultado fundamentales para diseñar la red ciclista (ibid., p.29):
1. Reducir el número de encuentros entre los ciclistas y el tráfico de automóviles que circula a velocidad elevada.

2. Reducir las diferencias de velocidad entre modos (bicicletas y motorizados) en aquellas vías donde la separación sea imposible o difícil de encajar por otros motivos (tráfico de vehículos pesados, actividad de carga/descarga, etc.).

Estos dos criterios han ayudado a tomar una decisión concreta sobre las dos tipologías básicas de tratamiento ciclista existentes hoy en la ciudad: la segregación mediante carril-bici delimitado en calzada o acera-bici específica, o bien la integración en coexistencia con el tráfico, con los peatones y también con el transporte público (Fig. 4).

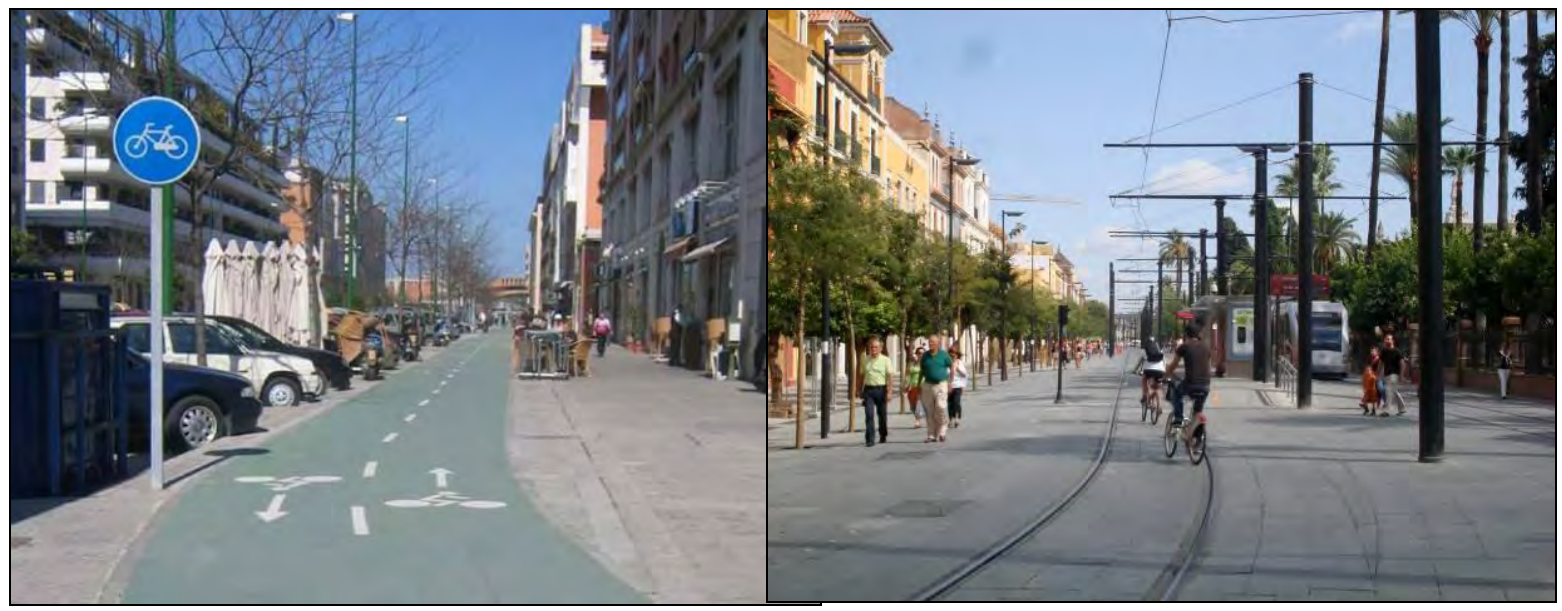

Figura 4: Segregación mediante carril-bici (izqda.), y coexistencia con peatones y transporte público. Fuente: Izqda. www.carrilesbicisevilla.blogspot.com. Dcha: realización propia (2009).

La separación física (ibid., p.29) "se ha adoptado en las vías principales de tráfico motorizado donde existe espacio para la bicicleta, en bastantes casos ganado a la doble fila de aparcamiento". Cuando no ha sido posible la segregación, se ha procurado reducir la velocidad de los automóviles mediante actuaciones de calmado de tráfico, integrando así la bicicleta en las líneas estratégicas que definen la jerarquía del viario. El documento también concreta que "en las zonas centrales de la ciudad y en las zonas centrales de los barrios la prioridad debe ser facilitada a los medios no motorizados" (ibid., p.29).

El "Plan de la Bicicleta de Sevilla, 2007-2010" (Gerencia de Urbanismo, 2007), por su parte, propone medidas complementarias de fomento de la bicicleta, destacando aquellas encaminadas a integrar la bicicleta en el sistema intermodal de transportes. Este documento destaca por 
"sentar las bases de una estrategia global de fomento del uso de la bicicleta como medio de transporte urbano en Sevilla. También establece una serie de medidas infraestructurales de apoyo al desarrollo de vías ciclistas y diseña un conjunto de programas sectoriales" (ibid., p.16).

El Plan hace suyos los 2 criterios fundamentales adoptados en el documento de Bases y Estrategias, ya citados, para el diseño de la red de vías ciclistas, y agrega a continuación una serie de directrices complementarias: destaca entre ellas la elección de una red de carriles separada físicamente (excepto en las zonas de coexistencia), en su mayoría en plataforma de

acera, a costa del espacio destinado al aparcamiento en batería u ocupado por la doble fila, y siendo los carriles bidireccionales de 2,5 metros de anchura media.

El Plan define el programa de desarrollo de la red de vías ciclistas, aborda la estrategia de fomento de la bicicleta en el casco histórico (que es considerado en general como "zona 30" o "zona 20"), y crea la Oficina Municipal de la Bicicleta. Caracteriza también el sistema de bicicleta pública que plantea implantar, y que actualmente cuenta con 2.500 bicicletas y 250 estaciones (Fig. 5).

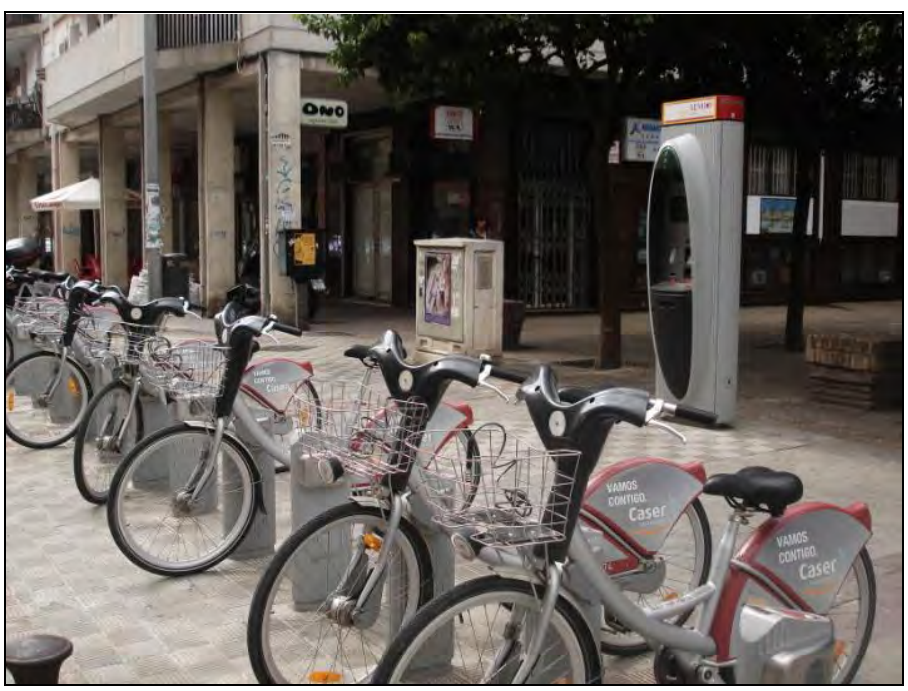

Figura 5: Sistema de bicicleta pública de Sevilla. Fuente: Realización propia (2009).

Estas medidas de fomento de la bicicleta se plantean gracias a que un trabajo de campo realizado en la primavera de 2006 certificaba que la ampliación y mejora de la red viaria para bicicletas constituía una notable demanda social. El siguiente documento analizado, la "Ordenanza Municipal de Circulación de Peatones y Ciclistas", aprobado en 2008, ha sido objeto de una fuerte controversia ${ }^{4}$ debido a que permite la circulación

\footnotetext{
${ }^{4}$ Fue denunciada por una Asociación de Vecinos, generando una Sentencia del Tribunal Superior de la Junta de Andalucía (TSJA) en la que se anulaban los artículos 16, 40, 41 y 43, y parte de los artículos 44 y 48 . La Sentencia fue posteriormente recurrida por el Ayuntamiento de Sevilla y A Contramano, y finalmente el Tribunal Supremo ha considerado conforme a derecho la referida Ordenanza, anulando así la Sentencia del TSJA.
}

de bicicletas por áreas peatonales, aunque con las lógicas restricciones para los ciclistas. Se reconocen 5 condiciones para el tránsito de bicicletas por aceras y zonas peatonales: 1) Que en la vía no exista carril-bici; 2) Que la anchura (de la acera) sea superior a 5 metros, y al menos haya 3 metros libres; 3) Que se circule a velocidad reducida (menos de $10 \mathrm{~km} / \mathrm{h}$ ); 4) Que se respete en todo momento la prioridad peatonal; y 5) Que no se realicen maniobras bruscas ni se circule a menos de 1 metro de las fachadas.

Finalmente, el "Estudio sobre el Uso de la Bicicleta en Sevilla" (Delegación de 
Infraestructuras para la Sostenibilidad, 2010) ofrece unas cifras globales de viajes en bicicleta en día laborable sin Iluvia, para el año 2009, gracias a la realización de unos aforos y una posterior modelización con los datos de una encuesta domiciliaria que se había realizado en 2007. Los datos son deslumbrantes: "de 41.744 desplazamientos diarios en bicicleta en 2007, se ha pasado a 52.780 desplazamientos diarios, lo que supone un incremento del $26,4 \%$ en sólo 2 años, que equivale a un crecimiento anual acumulado del 12,4\%" (ibid., p.10). En 2007, la movilidad en bicicleta suponía ya el 3,2\% del total de reparto modal, esto es, considerando los desplazamientos a pie, que constituían el $36,5 \%$ del total (cuadro 2).

\begin{tabular}{|ccc|}
\hline $\begin{array}{c}\text { Modo } \\
\text { A pie }\end{array}$ & Número de viajes (día laborable) & reparto modal (\%) \\
\hline Coche & 475.120 & $36,5 \%$ \\
\hline Transporte público & 473.021 & $36,3 \%$ \\
\hline Moto & 254.463 & $19,5 \%$ \\
\hline Bicicleta & 59.033 & $4,5 \%$ \\
\hline
\end{tabular}

Cuadro 2: Reparto modal de los viajes internos totales de Sevilla. Fuente: Delegación de Infraestructuras para la Sostenibilidad (2010), a partir de datos de la Encuesta Domiciliaria de Movilidad de 2007.

Pero si se dejan a un lado los desplazamientos a pie para considerar exclusivamente la movilidad mecanizada, se obtiene que los referidos 52.780 desplazamientos diarios en bicicleta suponen el
$6,6 \%$ de la movilidad mecanizada. La línea 1 del metro capta, sorprendentemente, un número de viajeros considerablemente menor (cuadro 3).

\begin{tabular}{ccc}
\hline $\begin{array}{c}\text { Modo } \\
\text { Coche }\end{array}$ & Número de viajes (2009, estimado) & reparto modal (\%) \\
\hline Autobús urbano & 425.500 & $52,8 \%$ \\
\hline Tranvía & 224.600 & $27,9 \%$ \\
\hline Metro Línea 1 & 16.000 & $2 \%$ \\
Moto & 21.200 & $2,6 \%$ \\
Bicicleta & 65.000 & $8,1 \%$ \\
\hline
\end{tabular}

Cuadro 3: Reparto modal de los viajes mecanizados internos de Sevilla en día laborable sin lluvia.

Fuente: Delegación de Infraestructuras para la Sostenibilidad (2010).

Además de esta cuantificación de la movilidad ciclista, se ha realizado una encuesta a ciclistas que permiten su caracterización en cuanto a motivo de viaje, recurrencia o modo alternativo de 
desplazamiento, lo que ha permitido cifrar el impacto que la consolidación de la bicicleta ha tenido sobre el resto de modos, esto es, el cambio modal efectivo hacia la bicicleta desde el resto de modos de transporte.

Finalmente, se han estimado los beneficios que ha supuesto este trasvase modal en términos de ahorro energético y disminución de emisiones de gases de efecto invernadero, obteniéndose

"un ahorro de energía primaria equivalente a 448,06 tep/año y de emisiones a la atmósfera de 1.178,07 $\mathrm{tCO}_{2}$ eq/año. Si se acepta el convencionalismo de que cada tonelada de $\mathrm{CO}_{2}$ que se deja de emitir a la atmósfera equivale a la plantación de 30 árboles, se tiene que el ahorro producido equivale a la plantación de casi 36.000 árboles" (ibid., p.19).

\section{Entrevista participada}

La entrevista a Ricardo Marqués Sillero y José García Cebrián, cuya narrativa completa se encuentra disponible en el proyecto de Máster en el que este artículo se basa, ha permitido incorporar aspectos relevantes procedentes de los movimientos sociales y del mundo técnicopolítico. Es justo reconocer el papel fundamental que, desde la década de 1980, han tenido los movimientos sociales ${ }^{5}$ en la promoción de la bicicleta en Sevilla. Su aliento e implicación en innumerables marchas reivindicativas y jornadas técnicas a lo largo de los últimos 30 años propiciaron un clima social favorable a la bicicleta y estimularon un marco institucional idóneo para la implementación de medidas a favor de la movilidad ciclista. Ello supone un claro ejemplo de interrelación entre civitas, polis y urbs, "las 3 dimensiones del hábitat social que se relacionan entre sí de modo dialógico y recursivo" (De Manuel Jerez, 2010, p.16). La civitas ha influido

${ }^{5}$ Grupo Ecologista Autónomo Sevillano (GEAS), Asociación Amigos de la Bici y, muy especialmente, A Contramano, Asamblea Ciclista de Sevilla, desde su constitución en 1987. significativamente en la polis, cuyas decisiones para la incorporación de la bicicleta en el sistema de movilidad de la ciudad han transformado la urbs. El hábitat social ha cambiado en Sevilla con la bicicleta.

La celebración de numerosas jornadas, convocatorias de marchas, reuniones y actos públicos en torno a la bicicleta, y la aparición de textos específicamente dedicados a la bicicleta (libros, artículos, posters, folletos, webs, etc.) han constituido un modo de circulación de discursos (Malpica, 2010). Las marchas ciclistas han evolucionado con los años, pasando de ser locales a metropolitanas con la celebración del Día Metropolitano de la Bicicleta. El Pacto Andaluz de la Bicicleta supuso, en su momento, el salto a la perspectiva regional. La celebración de la Masa Crítica durante los años 2005 y 2006 resultó vital para apoyar el proceso de construcción de la red de vías ciclistas. Más recientemente, desde el pasado otoño de 2010, se celebra la iniciativa Ciclovía (aquí llamada Ciclovida), procedente de algunas ciudades americanas, consistente en cerrar una avenida principal al tráfico motorizado durante una mañana de domingo al mes, para destinarla a los modos no motorizados y a los juegos y actividades recreativas. Supone un ejercicio de promoción de los tiempos lentos, búsqueda de contacto social y utilización compartida del espacio urbano en un ambiente lúdico y festivo (Fig. 6).

Los entrevistados valoran muy positivamente la celeridad con la que se ha ejecutado la red de 120 km de vías ciclistas, que abarca la práctica totalidad del municipio, así como su bajo coste económico, 32 millones de euros, con los cuales también se han ampliado acerados y calmado el tráfico a medida que se ejecutaban las propias vías. 

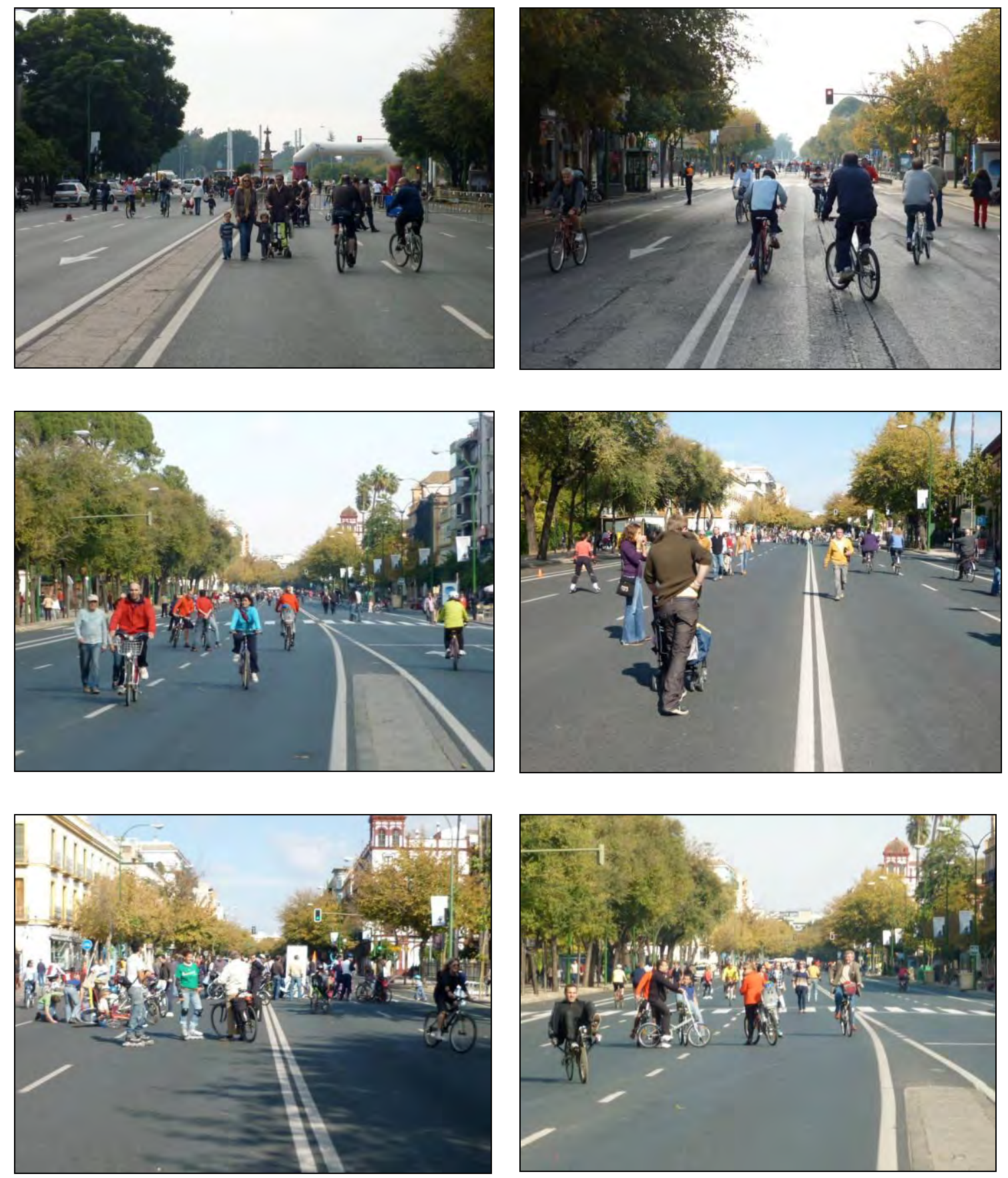

Figura 6: Fotografías de la Ciclovida celebrada en Sevilla el pasado 7 de noviembre de 2010, en el tramo comprendido entre La Florida y la Avenida Menéndez Pelayo. Fuente: Realización propia (2010).

La red de vías ciclistas de Sevilla, en cuyo planteamiento y diseño las dos personas entrevistadas han intervenido de manera decisiva, presenta las siguientes características fundamentales: 1) Continuidad física (120 km), que le aporta utilidad; 2) Conectividad, que le aporta funcionalidad; 3) Segregación, que le proporciona seguridad; 4) Planitud, que le proporciona confort; y 5) Bidireccionalidad, que le genera visibilidad.

Con respecto a la cuantificación de la movilidad ciclista en Sevilla, los entrevistados actualizan el dato de 52.800 desplazamientos diarios estimados en 2009, y señalan que la progresión en el uso de la bicicleta ha seguido su línea ascendente, estimándose en 2010 no menos de 70.000 desplazamientos diarios en bicicleta; puede que incluso más, en una cifra cercana a 
80.000. Ello ha sido gracias, probablemente, a la muy notable brevedad de tiempo con la que se ha implantado la red de vías ciclistas, y la enorme respuesta ciudadana a la misma, fruto de cierta tradición local de ciclismo urbano (Malpica, 2010). Otras dotaciones y medidas municipales, como la implantación de 5.728 aparcamientos para bicicletas privadas en la vía pública o la mejora de la incipiente señalización de tráfico aplicada al nuevo modo de movilidad, también han contribuido al auge de la bicicleta.

Por su parte, la constitución de la Oficina Municipal de la Bicicleta ha servido de empuje institucional, aseguran, para coordinar e impulsar todas las actuaciones municipales de fomento de la movilidad en bicicleta.

No se puede olvidar la puesta en servicio, en julio de 2007, del servicio municipal de alquiler de bicicletas públicas SEVICI. Este servicio constituye un factor determinante en la ampliación del número de ciclistas urbanos, en especial entre los jóvenes, las personas con bajos recursos y los usuarios preocupados por los robos de las bicicletas de su pertenencia. Ciertos especialistas señalan que en estos perfiles de nuevos ciclistas, el alquiler es en muchos casos un recurso provisional, útil durante una etapa de adaptación para comprobar la funcionalidad de esta modalidad de transporte y que termina desembocando en la compra de su propia bicicleta en propiedad (Malpica, 2010).

Los servicios de intermodalidad en los que interviene la bicicleta han mejorado significativamente en el área de Sevilla, aseguran los entrevistados. Un buen ejemplo está en el Proyecto Bus+Bici, del Consorcio de Transportes del Área Metropolitana, que incluye con el ticket de autobús metropolitano el acceso a una de las 180 bicicletas públicas de préstamo gratuito (utilizadas anualmente por unas 27.000 personas), y a los nuevos aparcabicis reservados de la estación de autobuses de Plaza de Armas. Recientemente, el pasado 22 de noviembre de 2010, el Tribunal Supremo de Justicia ha considerado conforme a derecho la Ordenanza de Circulación de Peatones y Ciclistas de Sevilla, anulando de este modo la Sentencia del TSJA que invalidaba los artículos 16, 40, 41, 43 y parte de los artículos 44 y 48 de la normativa. Considera el Supremo que la Ordenanza no infringe la Ley de Tráfico ni el Reglamento General de Circulación. De este modo, avala las tesis del Ayuntamiento y de A Contramano en lo que respecta a la legalidad de permitir el tránsito de bicicletas por aceras y zonas peatonales bajo los 5 condicionantes expresados con anterioridad. Los entrevistados comentan el fallo del Supremo y se muestran de acuerdo con el espíritu de la Ordenanza de Circulación.

La entrevista participada finaliza con un último repaso a las causas del auge de la bicicleta en la ciudad. Afirman los entrevistados que el rotundo auge de la bicicleta en Sevilla se debe, sencillamente, a que le resulta útil y funcional a la ciudadanía. La población la utiliza masivamente porque le resuelve satisfactoriamente su necesidad de efectuar un desplazamiento urbano de pocos kilómetros, ahorrando tiempo y dinero. Consideran también que las actuaciones de calmado de tráfico, peatonalización y fomento de la movilidad en bicicleta están provocando un importante ahorro de energía y contaminación a la atmósfera, y ello permite que la sociedad sevillana se posicione mejor de cara al cambio global y a la previsible crisis energética futura. Adicionalmente, la promoción de tiempos lentos y la incorporación al sistema de movilidad de la ciudad de aquellos grupos sociales hasta ahora perjudicados (niños, personas mayores, etc.) puede suponer un ejercicio de inteligencia compartida de la ciudad. 


\section{Discusión}

La especie humana ha protagonizado una explosión demográfica y urbana en los últimos 250 años, pero que es particularmente intensa desde mediados del siglo $\mathrm{XX}$, y que está acompañada de tipologías edificatorias entre las que dominan las de baja densidad y de un consiguiente uso masivo del automóvil privado, lo cual intensifica el metabolismo de las metrópolis mundiales. Las causas de la urbanización del planeta se encuentran en los procesos de innovación tecnológica, universalización del acceso al automóvil y abaratamiento progresivo de los costes del transporte. La ciudad difusa, además, ha transformado la realidad de los sistemas urbanos y alterado sus lógicas económicas, sociales, físicas y territoriales.

Concretamente, la actual civilización urbanoindustrial destaca especialmente por el uso tan intenso que hace del flujo de energía primaria del planeta. En la actualidad, se consumen anualmente 12.000 millones de toneladas equivalentes de petróleo, y se emiten anualmente a la atmósfera 30.000 millones de toneladas (30 $\mathrm{Gt})$ de $\mathrm{CO}_{2}$ (IPPC, 2011). Los esfuerzos por incrementar la eficiencia y reducir la contaminación suelen tener pobres resultados por enmarcarse dentro del paradigma económico convencional y no discutir el objetivo general de incrementar el crecimiento. Si verdaderamente se desea reducir de forma drástica las emisiones en el curso de unas pocas décadas, se ha de aceptar un importante y crítico descenso en el consumo de energía, empezando por los países más ricos e industrializados. Ello exige replantear por completo los modelos de organización urbana y territorial, y revisar los sistemas de movilidad y de gestión colectiva (agua, residuos,...), así como las formas de organización social, económica, laboral, administrativas, etc. Sugerimos que un buen comienzo sería recuperar el principio de "autosuficiencia conectada" (Gallart, 2009), de tal manera que los socioecosistemas urbanos procuren un reacoplamiento con el territorio y su base biofísica, si bien conectados a redes para tomar lo que no se es capaz de producir autónomamente. En Requejo (2011) se encuentran aportaciones que conectan el principio de la autosuficiencia con las redes y capacidades de las sociedades contemporáneas.

Por su parte, el inicio del fin de la era de los combustibles fósiles impactará con fuerza en las metrópolis y sobre el transporte motorizado y la agricultura industrializada (Fernández Durán, 2008). Sus efectos, junto a los de la actual crisis sistémica, de naturaleza multidimensional, pueden provocar una crisis civilizatoria de consecuencias imprevisibles. Para esquivarla, los socioecosistemas urbanos, en tanto sistemas complejos adaptativos, deben articular estrategias que les proporcionen una mayor resiliencia y capacidad de auto-eco-organización en el actual marco de Cambio Global.

Una estrategia que entendemos puede ser importante en esta dirección es el fomento de la movilidad a pie y en bicicleta, y la restricción de la que se produce en automóvil privado. Para ello es necesario un modelo urbano compacto, en el que la mayoría de los desplazamientos puedan realizarse a pie y en bicicleta, en condiciones de plena intermodalidad con sistemas públicos de transporte colectivo. En este marco, el uso de la bicicleta como medio de transporte tiene importantes ventajas, tanto personales como colectivas, destacando entre ellas su capacidad para aumentar la zona de clientela del transporte público, lo que incrementa su competitividad. Creemos que la intermodalidad entre la bicicleta y el transporte público puede ser la única opción de movilidad viable en aquellas zonas residenciales en baja densidad.

Los desplazamientos en bicicleta (y en general, toda la movilidad no motorizada) contribuyen a 
devolver la escala humana a la ciudad, la cual se encuentra amenazada por la extensión del automóvil y por la cultura de la velocidad e hipermovilidad imperantes. Para replantearse el concepto de movilidad hace falta antes discutir el concepto de tiempo, en especial los tiempos urbanos. Se hace cada vez más necesario estimular los tiempos lentos en la ciudad, lo cual permite que los ciudadanos recobren la conciencia sobre sí mismos y se revierta la dinámica que tiende a proyectar las ciudades fuera de sí mismas, devolviéndoles la escala humana. La movilidad peatonal y ciclista constituye una excelente forma de promocionar los tiempos lentos y recuperar la dimensión simbólica de las ciudades. Maximiza los contactos entre ciudadanos y permite nuevos usos del espacio y los paisajes, al suponer la interacción dinámica con el entorno y los paisajes urbanos, que se ven modificados a cada paso o pedalada. El paisaje se mueve y se transforma a medida que se avanza en bicicleta, y el descubrimiento e interpretación de los paisajes fundantes necesita un tiempo lento. Consideramos que saber gestionar los tiempos cambiantes en la ciudad, respondiendo a los diferentes tiempos de los ciudadanos, es signo de una ciudad inteligente que es capaz de valorar y hacer operativa la ecología de saberes que su propia historia le ha ido otorgando. Estimamos que la promoción de los desplazamientos en bicicleta puede mejorar la inteligencia compartida de la ciudad, por las siguientes razones:

- Incorpora a estos medios de transporte blandos a grupos sociales antes marginados en un escenario de movilidad fundamentalmente motorizada.

- Permite superar jerarquías sociales y facilitar el contacto y la comunicación ciudadana, garantes de la cohesión social.

- Supone una reconsideración completamente diferente de los tiempos y los espacios urbanos, siendo sensibles a los diferentes tiempos de los ciudadanos y buscando un nuevo equilibrio urbano en el que prime el interés general por encima del interés particular.

La ciudad de Sevilla no ha contado con una red de carriles-bici hasta tiempos muy recientes. Hasta hace cinco años sólo existían tramos inconexos entre sí, que los hacía prácticamente inútiles para el transporte utilitario. Desde 2007, en cambio, existe una red integrada de $120 \mathrm{~km}$ de vías ciclistas que abarca la práctica totalidad del municipio, además de un sistema público de alquiler de bicicletas que cuenta con 2.500 unidades y 250 estaciones repartidas por toda la ciudad, junto a otras medidas de índole administrativo, educativo, social, etc. La construcción de estas vías ciclistas, con un coste de 32 millones de euros, ha supuesto una práctica económica para la administración, en relación a los beneficios colectivos que luego se han obtenido. Los datos aportados en el apartado de revisión bibliográfica apuntan a que el número de desplazamientos en bicicleta se ha duplicado prácticamente en 4 años, entre los años 2007 a 2010. Sevilla se encuentra en la actualidad a la cabeza de las ciudades españolas en el uso de la bicicleta como medio habitual de transporte, en relación a su población. $Y$ así lo están reconociendo muchas ciudades de nuestro entorno, federaciones de ciclismo urbano, asociaciones, etc. Prueba de ello ha sido la elección, por parte de la Federación Europea de Ciclistas, de Sevilla para la organización del congreso Velocity 2011, el más importante del mundo en cuanto a promoción de la bicicleta como medio de transporte urbano, que tuvo lugar el pasado marzo del presente año.

Por otra parte, en el proceso de toma de decisiones sobre la tipología de la red ciclista de 
Sevilla, los técnicos y políticos implicados se decantaron por una red fundamentalmente bidireccional. La unidireccionalidad 0 bidireccionalidad de las vías puede ser objeto de discusión, ya que no hay una única solución, dependiendo en cada caso del espacio disponible, trama urbana y nivel de cultura ciclista en la ciudad. Lo cierto es que los carriles bidireccionales cuentan con 4 ventajas fundamentales, que quisiéramos subrayar:

- Reducen las intersecciones con el tráfico motorizado a la mitad, con lo que aumenta la seguridad y la fluidez de los flujos.

- Generan más visibilidad ciclista en los cruces, lo que también redunda en un aumento de la seguridad.

- Moderan la velocidad de circulación ciclista, al existir otros usuarios circulando próximos y en sentido opuesto, con lo que se reducen conflictos con los peatones.

- Permiten el cruce e intercambio visual con otros ciclistas, generando complicidad y la apariencia de que el flujo ciclista es mayor, impresión que tiene tanto el propio usuario que se desplaza en bicicleta como un observador situado fuera del carril (un peatón desde la acera o un automovilista desde la calzada), lo que facilita su convencimiento de que la red es útil y la inversión económica ha sido acertada.

Hay ejemplos de ciudades europeas, en cambio, con vías unidireccionales, que suelen permitir una mayor velocidad de desplazamiento. Normalmente, esta tipología aparece en ciudades del ámbito anglosajón y fuerte tradición ciclista, donde las vías ciclistas no son invadidas por otros usuarios, la velocidad a la que se desplaza el ciclista suele ser considerablemente mayor que en Sevilla, y donde un ciclista circulando próximo y en sentido contrario sería percibido más como un peligro que como una circunstancia amable. El caso de Sevilla es diferente. Si bien ha existido históricamente un amplio uso de la bicicleta en relación a los estándares de las ciudades españolas, que sobrevivió al "desarrollismo" de los 60 y llegó a mostrar, en un aforo de 1984, una cifra de 30.000 desplazamientos diarios (Mateos et al., 1986), que se estima que se mantuvo e incluso pudo aumentar levemente en el siguiente decenio a pesar de la falta de seguimiento específico $^{6}$, la situación de la bicicleta era marginal antes de la construcción de la infraestructura ciclista, especialmente si la comparamos con los estándares europeos. El contexto social y de cultura ciclista también era muy diferente. A pesar de los éxitos de las "masas críticas" celebradas durante 2005 y 2006 para apoyar el proceso de promoción de la bicicleta, es justo reconocer que también había rechazo por parte de ciertas agrupaciones de taxistas, comerciantes y vecinos. La utilización de la bicicleta no puede generalizarse entre las personas mayores o aquellas personas que tienen que cubrir grandes distancias entre su domicilio y su lugar de trabajo o estudio. La cultura del automóvil y la velocidad estaba presente, y de hecho aún lo sigue estando en ciertos grupos sociales. Los comerciantes y taxistas son colectivos particularmente reticentes a los cambios. Se necesitaba en 2006 y 2007, y aún hoy, grandes dosis de pedagogía para vencer las resistencias. En este marco de conflicto social en torno a la construcción del llamado "carril-bici", creemos que la solución adoptada en su momento de apostar por la bidireccionalidad de las vías fue acertada: las 4 ventajas apuntadas líneas arriba con las que cuentan las vías bidireccionales eran especialmente pertinentes en Sevilla para superar el conflicto social. Resultaba muy importante, en aquel momento, maximizar la seguridad en los desplazamientos y en los

\footnotetext{
${ }^{6}$ Lamentablemente, los estudios posteriores de movilidad no han incluido un análisis específico de la situación de la bicicleta, relegándola al apartado de "otros".
} 
cruces, y de camino moderar la velocidad de circulación ciclista, para reducir las tensiones con los peatones, al principio perplejos ante la novedad. Consideramos que la fluidez de los flujos y su mayor visibilidad resultó fundamental para convencer a los escépticos y "acostumbrar" a los peatones a la presencia de ciclistas en las vías. En líneas generales, los temidos atropellos de peatones por parte de ciclistas no tuvieron lugar, a pesar de la injustificada alarma social inicial. Los peatones "aprendieron" con el tiempo a cruzar las vías ciclistas por los pasos habilitados para ello, al igual que ya hacían cuando cruzaban la calzada. Todo ello sin menoscabo, por supuesto, de la absoluta prioridad peatonal en las áreas peatones.

Quisiéramos dedicar unas líneas a enfrentar la dicotomía motorizado/no motorizado, frente a mecanizado/no mecanizado. Creemos que la distinción entre "mecanizado/no mecanizado" permite encubrir el carácter motorizado del coche, que no se pone de manifiesto de forma explícita, y sitúa la bicicleta junto al coche. En su lugar, estimamos más oportuno discriminar entre "motorizado/no motorizado", de manera que la bicicleta se acerque al peatón, y se subraye el carácter motorizado del coche. Además, por razones de mecánica y física termodinámica, la bicicleta debe situarse mucho más próxima al modo peatonal.

Con respecto al fallo del Tribunal Supremo anulando la sentencia del TSJA y considerando conforme a derecho la Ordenanza de Circulación de Peatones y Ciclistas, algunos medios han procurado transmitir la idea de que el referido fallo implica una permisividad total y absoluta en lo que respecta a la circulación de ciclistas por aceras y zonas peatonales. Creemos, por el contrario, que las determinaciones y el enfoque general de la Ordenanza responden a la nueva realidad urbana existente en la ciudad a raíz de la progresiva introducción de la bicicleta en su sistema de movilidad. Las peatonalizaciones de un buen número de plazas y avenidas, la construcción de la red de carriles-bici y la pacificación general del tráfico inauguran un nuevo escenario en el que la coexistencia de peatones y ciclistas circulando a bajas velocidades en las áreas peatonales está llamada a ser la normalidad, tal y como sucede en muchas ciudades europeas desde hace años.

El cambio de modelo de movilidad que ha protagonizado la ciudad de Sevilla en el último lustro con su apuesta por la movilidad en bicicleta, los tiempos lentos, el ahorro energético y la disminución de las emisiones contaminantes, puede constituir un ejercicio de respuesta al Cambio Global y de adaptación y anticipación a las perturbaciones e incertidumbre, así como un ejemplo de inteligencia compartida de la ciudad, especialmente por el cambio mental y social que subyace. Esta última circunstancia llama la atención, en una ciudad que destaca por haber albergado iniciativas torpes y miopes. Pero lo cierto es que la integración de la bicicleta en el sistema de movilidad dota a la ciudad de resiliencia socioecológica, en tanto que sistema adaptativo complejo, y le permite asumir las perturbaciones y alcanzar un equilibrio dinámico con el que afrontar los inevitables y profundos cambios relacionados con la energía que están por llegar con el fin de la era de los combustibles fósiles y la presumible crisis energética mundial que le sucederá. En consecuencia, se ven aumentados los niveles de sostenibilidad general del sistema, mayores cuanto mayor sea la resiliencia generada.

En definitiva, la ciudad se auto-eco-organiza e inicia su aprendizaje (a través de las perturbaciones y tensiones) para adaptarse, siquiera parcialmente, a las exigencias del Cambio Global. La sostenibilidad de los sistemas 
urbanos en el siglo $\mathrm{XXI}$, -un siglo que tendrá en los cambios, las crisis y la incertidumbre sus rasgos definitorios-, pasa por saber aprovechar las oportunidades que les ofrece su condición de sistemas adaptativos complejos. La resiliencia socioecológica es clave para ello.

Esta auto-eco-organización del sistema y elevación de sus niveles de sostenibilidad puede sufrir un serio revés de confirmarse la derogación del Ilamado "Plan Centro", iniciativa recogida en el programa electoral que ha obtenido un respaldo mayoritario en las últimas elecciones municipales. El Plan Centro restringe el acceso en automóvil al casco histórico, a excepción de los residentes, y se enmarca en la consideración del centro de la ciudad como una zona 30 o zona 20 y en el modelo de movilidad ( $y$ de ciudad) por el que apostó la anterior corporación municipal. A pesar del respaldo mayoritario en las urnas del grupo político que plantea la derogación, las encuestas apuntan a que una mayoría de los ciudadanos apoya el proceso de peatonalización del casco histórico y de restricción de acceso en automóvil privado. Incluso se han celebrado protestas ciudadanas en los últimos días de julio de 2011 en contra de la derogación. Estas nuevas tensiones corroboran la complejidad de la movilidad urbana, sus múltiples y cambiantes actores, y los conflictos que en no pocas ocasiones aparecen entre la civitas y la polis. La derogación, además, cuenta en nuestra opinión con dificultades técnicas, pues es contraria al modelo de ciudad definido en el Plan General de Ordenación Urbana actualmente en vigor, que tiene carácter de norma de obligado cumplimento para la administración local. Consideramos que si se consuma la derogación, se estará interrumpiendo el proceso de progresiva incorporación de la bicicleta en la movilidad urbana de la ciudad, así como cancelando el modelo de movilidad en sí planteado para toda la ciudad, que tiene uno de sus más importantes pilares en la consideración del centro como zona 20 o zona 30 con prioridad para los modos no motorizados.

\section{Referencias}

AUGÉ, Marc. Por una antropología de la movilidad. Barcelona: Editorial Gedisa, 2007. 96 p.

AUGÉ, Marc. Elogio de la bicicleta. Barcelona: Editorial Gedisa, 2009. 109 p.

BOLETÍN OFICIAL DE LA PROVINCIA DE SEVILLA. Ordenanza de Circulación de Peatones y Ciclistas de la ciudad de Sevilla. BOP No 117, de 22 de mayo de 2008.

CRUTZEN, P. Geology of mankind, Nature, 2002, $n^{0} 415,23$.

DE MANUEL JEREZ, Esteban. Construyendo triángulos para la gestión social del hábitat. Hábitat y Sociedad, 2010, n¹, p. 13-37. www.habitatysociedad.us.es

DELEGACIÓN DE INFRAESTRUCTURAS PARA LA SOSTENIBILIDAD. Estudio sobre el uso de la bicicleta en la ciudad de Sevilla. Ayuntamiento de Sevilla, enero de 2010.

DUARTE, Carlos (coord.). Cambio Global. Impacto de la actividad humana sobre el sistema Tierra. Madrid: Consejo Superior de Investigaciones Científicas y Los Libros de la Catarata, 2009. 251 p.

ESTEVAN, Antonio. Contra el transporte, cercanía. Archipiélago: Cuadernos de crítica de la cultura, $\mathrm{n}^{\circ} 18-19$, pp. 33-42

ESTEVAN, Antonio y SANZ, Alfonso. Hacia la reconversión ecológica del transporte en España. Madrid: Bakeaz / Los Libros de la Catarata, 1996. 384 p.

FERNÁNDEZ DURÁN, Ramón. La explosión del desorden. La metrópoli como espacio de la crisis global. Madrid: Editorial Fundamentos, 1993.

FERNÁNDEZ DURÁN, Ramón. Un planeta de 
metrópolis (en crisis). Madrid: Editorial Zambra, Balade, CGT y Ecologistas en Acción, 2008.

FERNÁNDEZ DURÁN, Ramón. El Antropoceno: la crisis ecológica se hace mundial. Madrid: Ecologistas en Acción, 2010.

GALLART, Vicente. Hacia un hábitat autosuficiente. Diario EL PAÍS, 28 de marzo de 2009.

GERENCIA DE URBANISMO DE SEVILLA. Bases y Criterios para la Integración de la Bicicleta en la Movilidad Urbana de Sevilla. Aprobado por Consejo de Gobierno de la Gerencia de Urbanismo el 12 de mayo de 2005. Ayuntamiento de Sevilla, 2005.

GERENCIA DE URBANISMO DE SEVILLA. Plan de la Bicicleta de Sevilla, 2007-2010. Servicio Observatorio y Control de Procesos, Gerencia de Urbanismo. Ayuntamiento de Sevilla, 2007.

HOLLING, Crawford. Resilience and Stability of Ecological Systems. Annual Review of Ecology and Systematics, 1973, vol. 4, p.1-23..

ILLICH, Ivan. Energía y equidad. Barcelona: Six Barral, 1974.

IPPC (Panel Intergubernamental sobre el Cambio Climático). Summary for Policymakers. Special Report Renewable Energy Sources. New York, 2011.

JACOBS, Jane. Muerte y vida de las grandes ciudades. Madrid: Editorial Península, 1967.

JUNTA DE ANDALUCÍA. Monografía Sostenibilidad Ambiental Urbana. En Informe de Medio Ambiente 2006. Sevilla: Consejería de Medio Ambiente, 2007, p. 83-97.

LATOUCHE, Serge. La apuesta por el decrecimiento. ¿cómo salir del imaginario dominante? Madrid: Icaria editorial, 2008. 280 p.

MALPICA, Pedro. Efectos de las políticas públicas a favor de la bicicleta entre los ciclistas urbanos de Sevilla. En AEISAD. ¿Cómo hacer del deporte herramienta para el desarrollo? Madrid: Librerías Deportivas Esteban Sanz,
2010 , p. 200-215.

MATEOS, Antonio, SANZ, Alfonso, y Carlos TORRES. Estudio sobre actuaciones y políticas de potenciación de la bicicleta en el Área Urbana de Sevilla. Sevilla: Ayuntamiento de Sevilla, 1986.

MORIN, Edgar. Ciencia con conciencia. Barcelona: Anthropos, 1984. 376 p.

MORIN, Edgar. Introducción al pensamiento complejo. Barcelona: Editorial Gedisa, 1994.

NAREDO, José Manuel. La Economía en evolución. Historia y perspectivas de las categorías básicas del pensamiento económico. Madrid: Siglo XXI, 2003 (3 $3^{\text {a }}$ edición). 612 p.

NAREDO, José Manuel. Raíces económicas del deterioro ecológico y social. Más allá de los dogmas. Madrid: Siglo XXI, 2006. 320 p.

OJEDA, Juan Francisco. Ciudades, Metrópolis, Postmetrópolis y el uso de la Inteligencia Compartida. En Congreso La Ciudad Viva como Urbs, Quito, Julio de 2009.

PRIGOGINE, Illya. Time, structure and fluctuactions. Science, 1978, nº 201, p. 777-785.

REQUEJO, Juan. Territorio y energía: la autosuficiencia conectada. En Energías Renovables: Paisaje y Territorio Andaluz. Grupo de Estudios Avanzados sobre Territorio y Medio Ambiente, 2010.

RUEDA, Salvador. Ecologia urbana. Barcelona y la seva regió metropolitana com a referents. Barcelona: Beta editorial, 1995. 256 p.

SANZ, Alfonso. Calmar el tráfico. Pasos para una nueva cultura de la movilidad urbana. Madrid: Dirección General de Planificación, Ministerio de Fomento, 2008.

SANZ, Alfonso. La bicicleta y la pacificación del tráfico en los espacios urbanos. En VIII Congreso Ibérico La Bicicleta y la Ciudad, Sevilla, octubre de 2010.

SOUSA SANTOS, Sousa. El milenio huérfano. Ensayos para una nueva cultura política. 
Madrid: Editorial Trotta, 2005. 393 p.

TAIBO, Carlos. En defensa del decrecimiento. Sobre capitalismo, crisis y barbarie. Madrid: Los Libros de la Catarata, 2009. 160 p.

TAIBO, Carlos. Su crisis y la nuestra. Un panfleto sobre decrecimiento, tragedias y farsas. Madrid: Los Libros de la Catarata, 2010. 136 p.

VARELA, J.A. El coche, ese Centauro moderno con culo de escape, 2008. <http://www.eutsi.org/kea/ecologia/el-coche-esecentauro-moderno-con-culo-de-escape.html> (consultado el 9 de mayo de 2011)

WWF (World Wildlife Fund for Nature). Living Planet Report 2010. Gland, 2010.

\section{Cita del artículo}

MORALES, L. La movilidad ciclista como factor de sostenibilidad: breve análisis de su emergencia en la ciudad de Sevilla. Hábitat y sociedad, 2011, n² 2, p. 109-130. <www.habitatysociedad.us.es>.

http://dx.doi.org/10.12795/HabitatySociedad.2011.i2.06 